Tai Xi-Shi, Zhou Xiao-Jing, Liu Li-Li, Zhang Ai-Ling* and Wang Li-Hua

\title{
The crystal structure of 4-amino- $N^{\prime}$ - (4-aminobenzoyl)benzohydrazide monohydrate, $\mathrm{C}_{14} \mathrm{H}_{16} \mathrm{~N}_{4} \mathrm{O}_{3}$
}

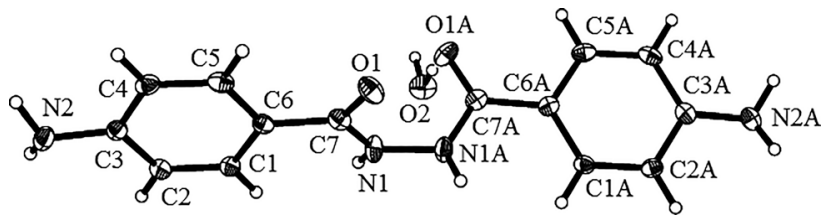

https://doi.org/10.1515/ncrs-2020-0476

Received September 15, 2020; accepted October 13, 2020; published online November 4, 2020

\begin{abstract}
$\mathrm{C}_{14} \mathrm{H}_{16} \mathrm{~N}_{4} \mathrm{O}_{3}$, orthorhombic, $P 2_{1} 2_{2} 2$ (no. 18), $a=8.0968(7) \AA$, $b=16.6829(17) \AA, c=5.3097(5) \AA, V=717.22(12) \AA^{3}, Z=2$, $R_{g t}(F)=0.0420, w R_{r e f}\left(F^{2}\right)=0.0816, \mathrm{~T}=293(2) \mathrm{K}$.
\end{abstract}

CCDC no.: 2036795

The molecular structure is shown in the figure. Table 1 contains crystallographic data and Table 2 contains the list of the atoms including atomic coordinates and displacement parameters.

Table 1: Data collection and handling.

\begin{tabular}{ll}
\hline Crystal: & Colourless block \\
Size: & $0.13 \times 0.12 \times 0.11 \mathrm{~mm}$ \\
Wavelength: & Mo $K \alpha$ radiation $(0.71073 \AA$ ) \\
$\mu:$ & $0.10 \mathrm{~mm}^{-1}$ \\
Diffractometer, scan mode: & SuperNova, \\
$\theta_{\text {max }}$, completeness: & $27.5^{\circ}, 97 \%$ \\
$N(h k l)_{\text {measured }}, N(h k l)_{\text {unique }}, R_{\text {int }}:$ & $2291,1490,0.025$ \\
Criterion for $I_{\text {obs }}, N(h k l)_{\text {gt }}:$ & $I_{\text {obs }}>2 \sigma\left(l_{\text {obs }}\right), 1224$ \\
$N(\text { param })_{\text {refined }}:$ & 110 \\
Programs: & Bruker [1], Olex2 [2], SHELx [3], \\
& Diamond [4]
\end{tabular}

*Corresponding author: Zhang Ai-Ling, College of Chemistry and Chemical Engineering, Weifang University, Weifang, Shandong 261061, P. R. China, e-mail: zhangal@wfu.edu.cn

Tai Xi-Shi, Zhou Xiao-Jing, Liu Li-Li and Wang Li-Hua, College of Chemistry and Chemical Engineering, Weifang University, Weifang, Shandong 261061, P. R. China. https://orcid.org/0000-0002-00501900 (T. Xi-Shi)

\section{Source of material}

The synthetic method of 4-amino- $N^{\prime}$-(4-aminobenzoyl) benzohydrazide monohydrate is as following: the mixture of $0.0755 \mathrm{~g}$ 4-aminobenzoic hydrazide $(0.5 \mathrm{mmol}), 0.0531 \mathrm{~g}$ thiocarbohydrazide $(0.5 \mathrm{mmol})$ and neodymium(III) nitrate hexahydrate were dissolved in $20 \mathrm{~mL}$ (water-ethanol = 1:1) and continully stirred at $70^{\circ} \mathrm{C}$ for $5.5 \mathrm{~h}$. After cooled to room temperature, the solution was filtered to a small beaker. The colorless crystals of 4-amino- $N^{\prime}$-(4-aminobenzoyl) benzohydrazide monohydrate were obtained by slow evaporation in 30 days.

\section{Experimental details}

The hydrogen atoms were positioned geometrically $(\mathrm{C}-\mathrm{H}=0.93 \AA, \mathrm{N}-\mathrm{H}=0.84-0.91 \AA$ and $\mathrm{O}-\mathrm{H}=0.85 \AA$ ) $)$. Their $U_{\text {iso }}$ values were set to $1.2 U_{\text {eq }}$ or $1.5 U_{\text {eq }}$ of the parent atoms.

Table 2: Fractional atomic coordinates and isotropic or equivalent isotropic displacement parameters $\left(\AA^{2}\right)$.

\begin{tabular}{lrrrr}
\hline Atom & $\boldsymbol{x}$ & $\boldsymbol{y}$ & $\boldsymbol{z}$ & $\boldsymbol{U}_{\text {iso }} / \boldsymbol{U}_{\text {eq }}$ \\
\hline $\mathrm{O} 1$ & $0.2071(2)$ & $0.46321(10)$ & $0.9185(3)$ & $0.0388(5)$ \\
$\mathrm{N} 1$ & $0.0086(3)$ & $0.45863(12)$ & $0.6211(4)$ & $0.0344(6)$ \\
$\mathrm{H} 1$ & $-0.065(4)$ & $0.4362(16)$ & $0.535(5)$ & $0.043(9)^{\star}$ \\
$\mathrm{N} 2$ & $0.2120(3)$ & $0.08664(13)$ & $0.7009(4)$ & $0.0340(6)$ \\
$\mathrm{H} 21$ & $0.244(3)$ & $0.0603(16)$ & $0.843(5)$ & $0.041^{*}$ \\
$\mathrm{H} 22$ & $0.143(3)$ & $0.0603(16)$ & $0.613(5)$ & $0.041^{*}$ \\
$\mathrm{C} 1$ & $0.0663(3)$ & $0.29030(15)$ & $0.5576(5)$ & $0.0258(6)$ \\
$\mathrm{H} 1 \mathrm{~A}$ & 0.0053 & 0.3163 & 0.4337 & $0.031^{*}$ \\
$\mathrm{C} 2$ & $0.0859(3)$ & $0.20834(15)$ & $0.5456(5)$ & $0.0271(6)$ \\
H2 & 0.0370 & 0.1796 & 0.4153 & $0.033^{*}$ \\
$\mathrm{C} 3$ & $0.1785(3)$ & $0.16808(15)$ & $0.7274(4)$ & $0.0266(6)$ \\
$\mathrm{C} 4$ & $0.2468(3)$ & $0.21238(16)$ & $0.9245(5)$ & $0.0308(6)$ \\
H4 & 0.3063 & 0.1863 & 1.0499 & $0.037^{*}$ \\
C5 & $0.2271(3)$ & $0.29412(16)$ & $0.9353(5)$ & $0.0303(6)$ \\
H5 & 0.2751 & 0.3226 & 1.0669 & $0.036^{*}$ \\
C6 & $0.1366(3)$ & $0.33522(15)$ & $0.7532(4)$ & $0.0249(6)$ \\
C7 & $0.1201(3)$ & $0.42302(15)$ & $0.7733(4)$ & $0.0284(6)$ \\
O2 & 0.5000 & 0.5000 & $0.6775(5)$ & $0.0486(8)$ \\
H2O & 0.4233 & 0.4862 & 0.7777 & $0.073^{*}$ \\
\hline
\end{tabular}




\section{Comment}

Benzamide compounds may exhibit good biological activity in antitumor activity [5, 6], FGFR1 inhibitors [7], antibacterial agent [8], antialzheimer agent [9], and uPA inhibitor [10]. In our previous work, some benzamide compounds have been synthesized and structurally characterized [11, 12]. In this work, we synthesized a new benzamide compound, 4-amino- $N^{\prime}$-(4-aminobenzoyl)benzohydrazide monohydrate, and its structure has also been determined.

The molecular structure of 4-amino- $N^{\prime}$-(4-aminobenzoyl) benzohydrazide is shown in the Figure. The compound consists of one 4-amino- $N^{\prime}$-(4-aminobenzoyl) benzohydrazide monohydrate molecule and one water molecule. The bond distance of C-O is 1.241(3) $\AA$ (C7-01), which is similar to the $\mathrm{C}-\mathrm{O}$ bond length $[13,14]$, indicating the $\mathrm{C}-\mathrm{O}$ bond is double bond. The dihedral angle between two benzene rings ((C1-C2-C3-C4-C5-C6) and (C1A-C2A-C3A$\mathrm{C} 4 \mathrm{~A}-\mathrm{C} 5 \mathrm{~A}-\mathrm{C} 6 \mathrm{~A})$ ) is $65.7^{\circ}$. In the crystal packing, the molecules form a 3D structure through $\mathrm{N}-\mathrm{H} \cdots \mathrm{O}$ and $\mathrm{O}-\mathrm{H} \cdots \mathrm{O}$ intermolecular hydrogen bonds.

Author contribution: All the authors have accepted responsibility for the entire content of this submitted manuscript and approved submission.

Research funding: This project was supported by the National Natural Science Foundation of China (No. 21171132), the Natural Science Foundation of Shandong (ZR2014BL003), the project of Shandong Province Higher Educational Science and Technology Program (J14LC01) and Science Foundation of Weifang.

Conflict of interest statement: The authors declare no conflicts of interest regarding this article.

\section{References}

1. Bruker. SaInt and SADABS; Bruker Axs Inc.: Madison, Wisconsin, USA, 2000.
2. Dolomanov O. V., Bourhis L. J., Gildea R. J., Howard J. A. K., Puschmann H. OLEX2: a complete structure solution, refinement and analysis program. J. Appl. Crystallogr. 2009, 42, 339-341.

3. Sheldrick G. M. Crystal structure refinement with SHeLXL. Acta Crystallogr. 2015, C71, 3-8.

4. Brandenburg K. DIAmond. Visual Crystal Structure Information System. Ver. 4.0; Crystal Impact: Bonn, Germany, 2015.

5. Zhang X., He F., Zhang Q., Lü J., Xu A., Yu C., Qu Y., Wu J. Design, synthesis and evaluation of anti-tumor activities of chidamide derivatives. Chin. J. Org. Chem. 2019, 39, 1983-1989.

6. Chen T.-P., Jiang H.-W., Zhou J.-J., Li Z.-C., Huang W.-C., Luo Y.-F., Zhao Y.-L. Synthesis of $N$-substituted benzamide derivatives and their evaluation as antitumor agents. Med. Chem. 2020, 16, 554-561.

7. Xie Z.-X., Cheng D.-H., Luo L., Shen G.-L., Pan S.-W., Pan Y.-Q., Chen B., Wang X.-B., Liu Z.-G., Zhang Y., Ye F.-Q. Design, synthesis and biological evaluation of 4-bromo- $N$-(3,5-dimethoxyphenyl) benzamide derivatives as novel FGFR1 inhibitors for treatment of non-small cell lung cancer. J. Enzym. Inhib. Med. Chem. 2017, 138, 964-978.

8. Xia J., Feng B., Wen G., Xue W.-J., Ma G.-X., Zhang H.-M., Wu S. Bacterial lipoprotein biosynthetic pathway as a potential target for structure-based design of antibacterial agents. Curr. Med. Chem. 2020, 27, 1132-1150.

9. Aliabadi A., Mohammadi-Farani A., Bistouni J.-R. Synthesis and acetylcholinesterase inhibitory assessment of benzamide derivatives incorporated piperazine moiety as potential antiAlzheimer agents. J. Pharmaceut. Sci. Res. 2017, 9, 1598-1603.

10. Yu H.-Y., Gao D., Zhang X., Jiang L.-G., Hong Z.-B., Fang X., Yuan C., Wang J.-D., Huang M.-D. Synthesis of a weak basic uPA inhibitor and crystal structure of a complex with uPA. Chin. J. Struct. Chem. 2013, 32, 961-968.

11. Tai X.-S., Wang L.-H, Liu L.-L., Zhou X.-J. The crystal structure of (E)- $N^{\prime}$-((2-hydroxynaphthalen-1-yl)methylene)-2- phenylacetohydrazide. $\mathrm{C}_{19} \mathrm{H}_{16} \mathrm{O}_{2} \mathrm{~N}_{2}$. Z. Kristallogr. NCS 2019, 234, 723-724.

12. Tai X.-S., Li P.-F. The crystal structure of $(E)-N^{\prime}$-(pyridin2-ylmethylene)pyrazine-2-carbohydrazide. $\mathrm{C}_{11} \mathrm{H}_{9} \mathrm{~N}_{5} \mathrm{O}$. Z. Kristallogr. NCS 2018, 233, 121-122.

13. Tai X.-S., Guo H.-M., Guo Q.-Q. Synthesis, crystal structure and antitumor activity of a novel $\mathrm{Zn}$ (II) complex with 2(nicotinoyloxy)acetic acid ligand. Chin. J. Struct. Chem. 2018, 37, 1052-1056.

14. Li-Hua, W., Xi-Shi, T., The crystal structure of (E)-N'-(quinolin-2ylmethylene)furan-2-carbohydrazide monohydrate, $\mathrm{C}_{15} \mathrm{H}_{13} \mathrm{~N}_{3} \mathrm{O}_{3}$, Z. Kristallogr. Z. Kristallogr. NCS 2017, 232, 1038-1056. 